\title{
COMMUNICATION
}

\section{Catherine Roberts New AMS Executive Director}

\author{
Allyn Jackson
}

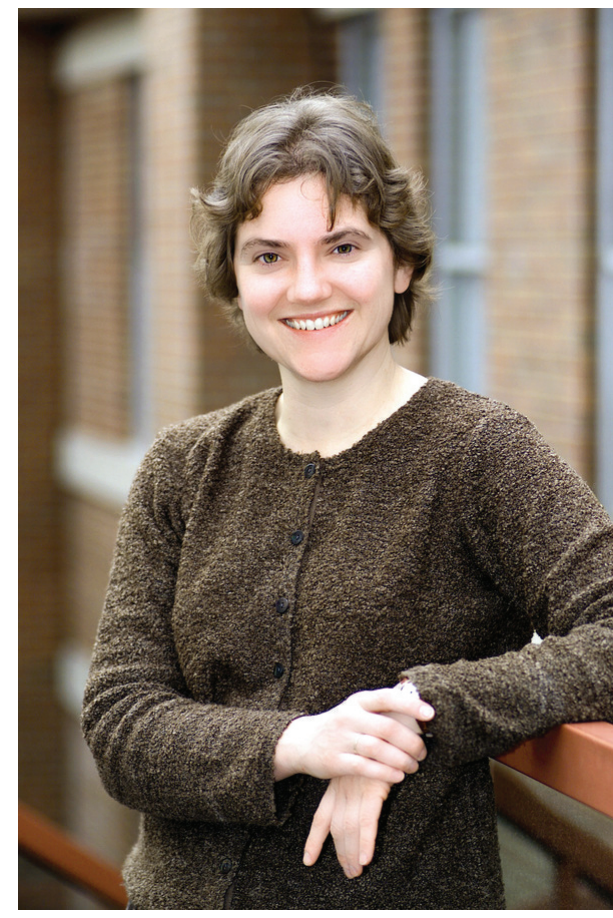

Catherine Roberts, professor of mathematics at the College of the Holy Cross, is the new executive director of the AMS. She succeeds Donald E. McClure, who served in the position since 2009. An article about McClure appeared in the August 2016 issue of the Notices.

In 2009, Catherine Roberts became chair of her department. Having been at the College of the Holy Cross for eight years, she was eager to tackle the educational and administrative challenges facing the department of twenty research-active faculty and 150 math majors. Little did

Allyn Jackson is senior writer and deputy editor of the Notices. Her email address is axj@ams . org.

For permission to reprint this article, please contact:

reprint-permission@ams.org.

DOI: http://dx.doi.org/10.1090/noti1433 she know that a nontrivial chunk of her time would be devoted to the seemingly minor issue of chalk.

The college had changed chalk brands, and the faculty found the new stuff didn't erase well and students had trouble seeing what was written over erased sections of chalkboards. The department tried a different brand, which proved inconsistent, as the raw materials came from various quarries. Another brand was liked by everyoneexcept the custodial staff, who found the dust of that particular chalk very difficult to clean up.

Roberts told the story of her "year-long quest for the perfect piece of chalk," as well as other oddities from her time as department chair, in "Chalk It Up to Experience," which appeared in the Chronicle of Higher Education in November 2011. That article captures Roberts's sense of humor, as well as her seriousness and tenacity in handling all kinds of issues, big and small.

These are some of the strengths Roberts brings to her new position of executive director of the AMS, which she began in August of this year. "I am pleased to be working with Dr. Roberts," said AMS President Robert Bryant. "She has a distinguished record of both research and service in the mathematics community and continues a tradition of excellence in the AMS Executive Director position."

If Roberts's chalk odyssey shows her detail-oriented side, the path she has taken in her research shows her ability to address problems of global significance, specifically, natural resource modeling. Her PhD, earned in 1992 at Northwestern University, was in the area of nonlinear integral Volterra equations. After three years on the tenure track at the University of Rhode Island, Roberts faced a "two-body problem" (her husband is an academic chemist) and moved to Northern Arizona University. There she got involved in a project to model the complex humanenvironmental interactions that occur in a recreational setting like the Grand Canyon. The resulting model, the Grand Canyon Trip Simulator, allows the National Park Service to test ways to issue permits for whitewater rafting on the Colorado River in order to reduce overcrowding and pollution. Reporting on this work appeared in "Mathematicians find path less travelled" 
Roberts herself has become someone who invites others into
(Nature, January 14, 2003), on the website of Science, and on National Public Radio.

Working in this area has brought some new experiences. "When I would publish an article on the nonlinear Volterra integral equations, I pretty much knew who would be interested in it," Roberts said. By contrast, "the Grand

Canyon work was of broad public interest. The park service would ask me to give a lecture in a library in Denver, or in an auditorium in Phoenix. There would be hundreds of people wanting to hear about this work and what we were trying to accomplish. That was so different for me as a mathematician."

As she continued to do research in environmental applications of mathematics, Roberts has led many activities that helped this nascent field grow and expand. She chaired the organizing committee of the 2007 World Conference on Natural Resource Modeling, held on Cape Cod, Massachusetts, and has organized many conference sessions on the topic, including AMS Special Sessions at the 2014, 2015, and 2016 Joint Mathematics Meetings; for the latter, her co-organizer was Shandelle Henson of Andrews University. Roberts has contributed to the Mathematics of Planet Earth activities that have taken place over the past few years and serves on the advisory committee for the Society for Industrial and Applied Mathematics Activity Group on this topic. Since 2004, she has been editor-in-chief of the journal Natural Resource Modeling.

Roberts did not start out in mathematics. As a student at Bowdoin College, she was orignally a French major. After she did well in a calculus class, the math department chair, William Barker, invited her to consider majoring in math. But she saw herself as a theater and language person, not a math person. "I was stuck with a stereotype that was blocking me from imagining myself as a mathematician," she recalled. "Bill Barker really convinced me I had what it took. He pulled me through the door and invited me in." Barker has continued to be her mentor and supporter throughout her career, a role he has played with countless other students, many of them women.

Roberts herself has become someone who invites others into mathematics. Her teaching has aimed to draw a wide variety of students into the field. Her courses are flavored with real-world applications and utilize instructional means beyond the traditional lecture format. She has passed her innovative ideas along to the next generation of college instructors by serving for three years as a workshop instructor and panelist for the Project NExT program (New Experiences in Teaching). Strongly committed to diversity, Roberts said she was "thrilled" about the AMS Office of Education and Diversity, established this year under the direction of Helen Grundman.
Roberts has had a significant impact on pre-college education through her work in the Intel Math Program. Based on the Vermont Mathematics Initiative founded by Kenneth Gross of the University of Vermont, the program offers an 80-hour professional development course in mathematics for K-8 teachers. Roberts got involved in the Intel program around the time her two sons were in school. When she would volunteer to do math activities in their classrooms, she found some teachers reacted enthusiastically, while others seemed nervous and wary. "And that troubled me," she recalled.

She began teaching in the Intel program when the state of Massachusetts adopted it in 2007. The program pairs a mathematician with a mathematics education specialist to collaborate on teaching the professional development course. "It's really wonderful, because the two instructors work together to help deliver the content and create that safe space for learning," Roberts remarked. "Having the expertise of a math educator along with the expertise of a mathematician is a really powerful model." Roberts has taught the course multiple times in Massachusetts and is now a "trainer of trainers," meaning that she travels to other states to train mathematicians to work in the program.

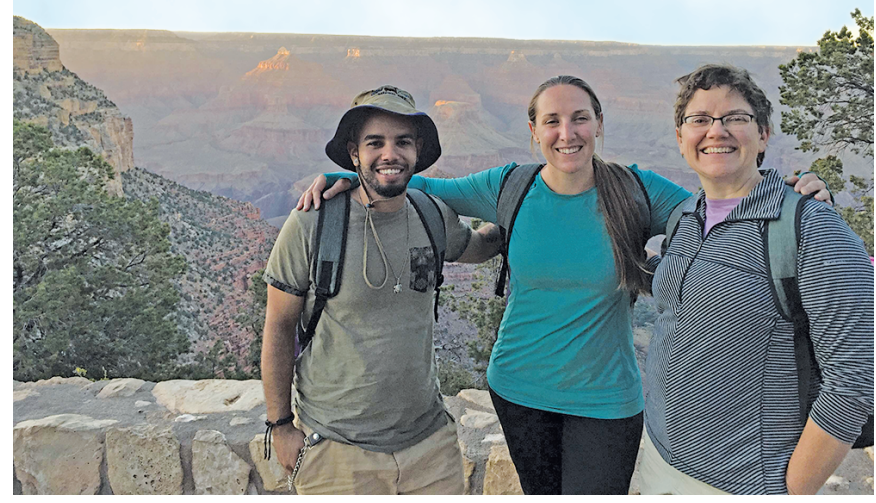

Catherine Roberts (right) with two former students, Jose Santiago (left), a senior at the College of the Holy Cross, and Joanna Bieri (middle), a professor at the University of Redlands, at the Grand Canyon in June. They were attending the 2016 World Conference on Natural Resource Modeling in Flagstaff, Arizona.

On top of all of this, Roberts has also been active in mathematical professional societies. For the AMS, she served on the Committee on Education, the Committee on Professional Ethics, and the Committee on Meetings and Conferences. For the latter, she chaired focus groups held at the Joint Mathematics Meetings in 2008 and 2009. She also has an extensive record of service to the Association for Women in Mathematics, the Society for Industrial and Applied Mathematics, and the Resource Modeling Association. 
Her involvement with professional societies makes her keenly aware of the central role of the AMS. "I've been involved with the AMS since I was a graduate student," she said. "The role of the AMS is broad and is essential." Mathematicians are well aware of many AMS activities, such as publishing and organizing meetings, she noted. But there are many others, such as raising awareness of mathematics among the general public and within the government, that are less well known but are crucial to supporting the field.

"I want to increase the awareness among our membership of all of the things the AMS is doing on behalf of mathematics, and how essential it is that we all support our professional society to continue to do that work," she said. "Helping keep those activities going is a way to keep our entire profession healthy. Every mathematician has, in my view, good reason to be a member of the AMS, to help do part of that work, because it is work that comes back and benefits them."

\section{Credit}

Headshot of Catherine Roberts, courtesy of College of the Holy Cross/Tom Rettig/Amy Forbes.

Photo of Catherine Roberts and students, courtesy of Catherine Roberts.

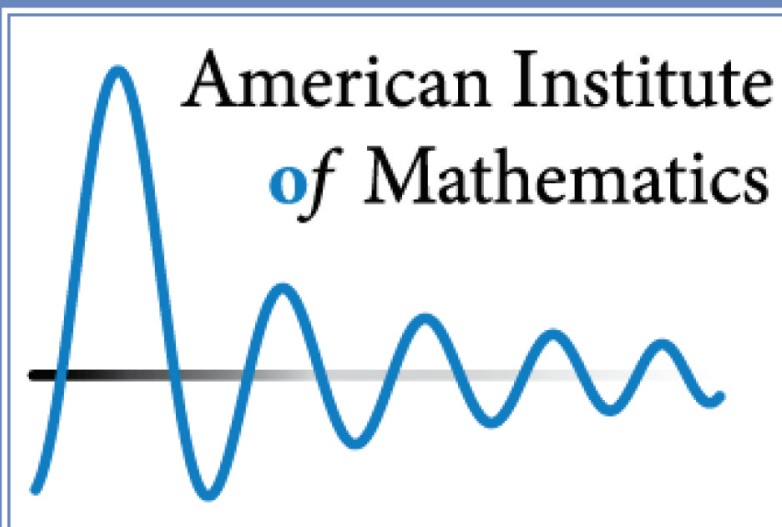

AIM, the American Institute of Mathematics, sponsors week-longactivities in allareas of the mathematicalsciences with an emphasis on focused collaborative research.

\section{Call for Proposals}

\section{Workshop Program}

AIM invites proposals for its focused workshop program. AIM's workshops are distinguished by their specific mathematical goals. This may involve making progress on a significant unsolved problem or examining the convergence of two distinct areas of mathematics. Workshops are small in size, up to 28 people, to allow for close collaboration among the participants.

\section{SQuaREs Program}

AIM also invites proposals for the SQuaREs program: Structured Quartet Research Ensembles. More longterm in nature, this program brings together groups of four to six researchers for a week of focused work on a specific research problem in consecutive years.

More details are available at:

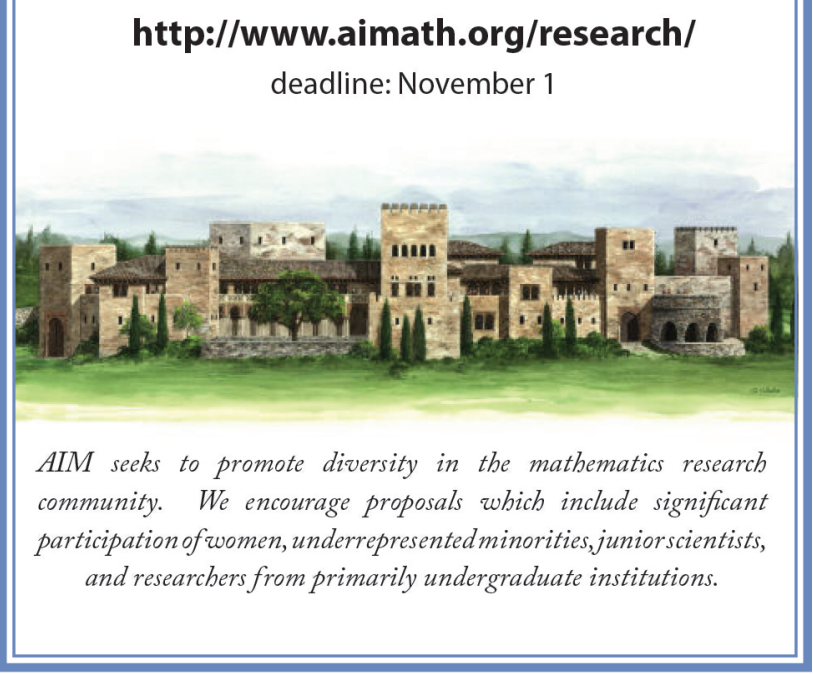

